Çukurova Üniversitesi Mühendislik Mimarlık Fakültesi Dergisi, 30(1), 257-269 ss., Haziran 2015

Çukurova University Journal of the Faculty of Engineering and Architecture, 30(1), pp. 257-269, June 2015

\title{
Reaktif Black 5 Boyar Maddesinin Aktif Karbon Üzerine Adsorpsiyonunun Kinetik ve Adsorpsiyon Modelleri Kullanılarak İncelenmesi
}

\author{
Fatma Elçin ERKURT ${ }^{* 1}$, Behzat BALCI ${ }^{1}$ \\ ${ }^{1}$ Çukurova Üniversitesi, Mühendislik Mimarlık Fakültesi, ÇevreMühendisliği Bölümü, Adana
}

Geliş tarihi: 08.04 .2015

Kabul tarihi: 07.05.2015

\begin{abstract}
Özet
Bu çalışmada Reaktif Black 5 (RB5) boyar maddesinin granül aktif karbon (GAK) üzerine kesikli deneyler ile adsorpsiyonu çalışılmış̧ır. Adsorpsiyon sürecini açıklayabilmek için iki ve ikiden fazla parametreli olmak üzere toplam 17 farklı izoterm modeli kullanılmıştır. İki parametreli modeller arasında 0,99'dan büyük regresyon katsayıları, heterojen yüzey adsorpsiyon süreçlerinin tanımlanmasında kullanılan Freundlich, Halsey ve Henderson izotermlerinden elde edilmiştir. Tüm adsorpsiyon izotermleri arasında en yüksek regresyon katsayısı $(0,998)$ Fritz-Schlunder modelinden hesaplanmıştır. Langmuir izotermi GAK'ın maksimum adsorpsiyon kapasitesini $23,58 \mathrm{mg} / \mathrm{g}$ olarak tahmin etmiş̧ir. Adsorpsiyon kinetiğini en iyi açıklayan modelin yalancı ikinci derece kinetik eşitliği olduğu bulunmuştur. Adsorpsiyon kinetiği üzerine GAK dozunun etkili olduğu tespit edilmiştir.
\end{abstract}

Anahtar Kelimeler: Tekstil atıksuyu, Langmuir, Elovich

\section{Investigation of Adsorption of Reactive Black 5 Dye onto Activated Carbon by Using Kinetic and Adsorption Models}

\begin{abstract}
In this study the adsorption of Reactive Black 5 (RB5) dye onto granulated activated carbon (GAC) has been studied in batch experiments. 17 different adsorption isotherms which have two and more than two parameters have been used to explain the adsorption process. Greater than 0.99 regression coefficients were obtained from Freundlich, Halsey and Henderson isotherms, defining adsorption of heterogeneous surfaces, among two parameters models. The highest regression coefficient $(0,998)$ was obtained from four parameters Fritz-Schlunder model among all adsorption isotherms. Langmuir isotherm predicted $23.58 \mathrm{mg} / \mathrm{g}$ maximum adsorption of GAC. The model that best describes the adsorption kinetics was found as the pseudo second order model. It was determined that GAC dosage was effective on adsorption kinetic.
\end{abstract}

Keywords: Textile wastewater, Langmuir, Elovich

*Yazışmaların yapılacağı yazar: Fatma Elçin ERKURT, Mühendislik Mimarlık Fakültesi, Çevre Mühendisliği Bölüm. Adana.eerkurt@cu.edu.tr 


\section{GİRIŞ}

Günümüzde insan faaliyetleri sonucu oluşan atıksular dünya için problem haline gelmiştir. Endüstriyel faaliyetler sonucu oluşan atıksular arıtılması zor birtakım kimyasal maddeler içerebilmektedir. Boyar madde içeren atıksular bu bağlamda oluşturacağı ekolojik problemlerden dolayı özel önem verilmesi gereken kirleticilerdendir. Dünya genelinde 10.000 tip farklı boya ve ortalama 700.000 ton miktarında boya kullanımı mevcuttur. Boyama işleminden sonra önemli miktarda boyar madde atıksulara ve alıcı ortama ulaşmaktadır. Boyar maddelerin sucul ortamlarda toksik, kanserojenik ve estetik problemlere neden olduğu bilinmektedir [1].

Reaktif boyar maddeler parlak yapıları hızlı uygulanabilirliği ve düşük maliyetinden dolayı tekstil endüstrisinde en yaygın kullanılan boyar madde tipidir [2]. Reaktif boyar maddeler suda çok iyi çözünebilir ve azoik yapılarından dolayı biyolojik parçalanmaya karşı oldukça dirençlidirler. Konvansiyonel arıtma prosesleri sonucunda çıkış sularında reaktif boyar madde kalıntıları mevcut olabilmektedir [3].

Adsorpsiyon prosesi boyalar maddeler gibi çözünmüş organik kirleticilerin sudan gideriminde yüksek kaliteli çıkış suyu sağladığından dolayı önem kazanmıştır [4]. Konvansiyonel atıksu arıtma metotlarına direnç gösterdiğinden dolayı birçok araştırmacı azo boyar maddeler üzerinde çalışmaya yönelmiştir $[5,6]$.

\subsection{Adsorpsiyon İzotermleri}

Adsorpsiyon izotermleri adsorpsiyon denge zamanına ulaştığı zaman adsorplanan moleküllerin katı ve sıvı faz arasında nasıl bir dağılım sergilediğini gösterir. Adsorpsiyon sürecinden elde edilen veri ile en iyi izoterm modellerinin elde edilmesi adsorpsiyon proseslerinin dizaynı için önemli bir adımdır. Adsorbe olan moleküllerin sıv1 fazdan ayrılarak adsorbent yüzeyine tutunmasının başarılı şekilde açıklanması, sıvı ve katı fazın dengeye ulaşma ayrımının iyi bir şekilde tanımlanmasına bağlıdır [7]. Adsorpsiyonun dengeye ulaşması ile ilgili bulgu adsorpsiyon prosesini anlamaktaki en önemli kısımdır.

Aktif karbon yüzeyine adsorpsiyon; iki, üç ve daha fazla parametre içeren adsorpsiyon modelleri ile açıklanabilir [8]. Genel olarak iki parametreli adsorpsiyon izotermleri lineer forma dönüştürülür ve parametreler grafik veya lineer regresyon yöntemiyle hesaplanabilir. Ancak üç veya daha fazla parametre içeren adsorpsiyon izotermlerinin grafik veya lineer regresyon yöntemiyle çözülmesi pek mümkün değildir. Bundan dolayı nonlineer regresyon yöntemiyle parametrelerin hesaplanması gerekmektedir. İkiden fazla parametre içeren eşitlikleri çözmek için korelasyonu maksimize edecek şekilde minimizasyon prosedürü uygulanır [9].

Bu çalışmada RB5 boyar maddesinin GAK üzerine adsorpsiyon sürecinin tanımlanabilmesi için iki ve ikiden fazla parametreli adsorpsiyon izotermleri ve çeşitli kinetik eşitlikler kullanılmıştır. RB5 boyar maddesinin GAK üzerine adsorpsiyonunu geniş anlamda izotermler açısından değerlendiren literatür kısıtlıdır. $\mathrm{Bu}$ bağlamda çalışmanın literatüre katk1 sağlayacağı ve aktif karbon ile boyar madde gideriminde tasarım parametrelerinin daha iyi belirlenebileceği düşünülmektedir.

\section{MATERYAL METOD}

\subsection{Materyal}

\subsubsection{Boyar Madde}

Adsorpsiyon çalışmasında adsorbat olarak RB5 boyar maddesi kullanılmıştır. Boyar madde Adana'da yerel bir tekstil firmasindan temin edilmiştir.

\subsubsection{Adsorbent}

Çalışmada adsorbent olarak Merck marka granül aktif karbon (CAS No: 7440-44-0) kullanılmıştır. Elek analizi ile ortalama karbon dane boyutu $1 \mathrm{~mm}$ olarak seçilmiştir. Karbon yoğunluğu $150-440 \mathrm{~kg} / \mathrm{m}^{3}$ molekül ağırlı̆̆ $12,01 \mathrm{~g} / \mathrm{mol}$, spesifik yüzey alanı $971,2 \mathrm{~m}^{2} / \mathrm{g}$ 'dır. 


\section{Metod}

\subsection{Analitik Yöntem}

S1v1 fazdaki kalıntı boyar madde konsantrasyonu spektrofotometrede $597 \mathrm{~nm}$ dalga boyunda hazırlanmış olan kalibrasyon eğrisi üzerinden gerçekleştirilmiştir (Chebios Opitimum-one).

\subsection{Deneysel Yöntem}

Adsorpsiyon çalışmasında $400 \mathrm{mg} / \mathrm{L}$ başlangıç RB5 konsantrasyonu ile 10 farklı GAC dozu $(1,2,3,4,5,6,7,8,9,10 \mathrm{~g})$ çalışılmıştır. Sulu çözelti hacmi $250 \mathrm{~mL}$ olup, $300 \mathrm{rpm}$ çalkalama şiddetinde adsorpsiyon gerçekleştirilmiştir. Adsorpsiyon sürecinin dengeye ulaşma anını tespit edebilmek için düzenli aralıklarla numune alınıp sıvı fazdaki kalıntı boyar madde konsantrasyonu ölçülmüştür. Adsorpsiyon çalışmaları $\mathrm{pH} 7$ 'de ve $20^{\circ} \mathrm{C}$ sabit sıcaklıkta gerçekleştirilmiştir.

\section{BULGULAR VE TARTIŞMA}

\subsection{Adsorpsiyon Denge Zamanı}

Adsorpsiyon bir denge tepkimesine benzemekte ve çözeltide kalan çözünen derişimi ile yüzeye tutulan çözünen derişimi arasında dinamik bir dengeye ulaşıncaya kadar sürmektedir. Dengenin bu durumunda çözünenin katı ve sıvı fazları arasında belirli bir dağılım gerçekleşmektedir. Adsorpsiyon dengesini belirtmek için sabit sıcaklıkta dengede çözeltide kalan çözünen derişimine karşı katı sorbentin birim ağırlığında adsorbe edilen çözünen miktarı grafiğe geçirilmektedir [10].

Denge zamanındaki adsorbentin birim ağırlığında (g) adsorbe edilen çözünen miktarı (mg) olan "q $\mathrm{q}_{\mathrm{e}}$ " değerini tespit etmek gerekmektedir. Ancak "qu" değerinin tam olarak elde edilmesi oldukça zordur. Bunun nedeni pek çok adsorpsiyon prosesinde adsorbat ve adsorbent arasındaki etkileşimin ilk hızlı tepkiden sonra oldukça yavaş meydana gelmesidir. Bu gibi durumlarda en yakın " $\mathrm{q}_{\mathrm{e}}$ " değeri seçilmektedir. Seçilen en yakın " $\mathrm{q}_{\mathrm{e}}$ " değerine ait denge zamanından sonraki zamanlardaki " $\mathrm{q}_{\mathrm{t}}$ ” değerleri $\mathrm{q}_{\mathrm{e}}$ değerine oldukça yakındır [11].

Yapılan deneysel çalışmada on farklı GAK dozu içinde adsorpsiyonun dengeye ulaşması süresinin 55 dakika olduğu tespit edilmiştir. $\mathrm{Bu}$ durumda izoterm verilerinin hesaplanmasinda 55. dakikadaki, $\mathrm{q}_{\mathrm{t}}(\mathrm{mg} / \mathrm{g})$ değeri $\mathrm{q}_{\mathrm{e}}(\mathrm{mg} / \mathrm{g})$ olarak seçilmiştir. Denge zamanını gösteren grafik Şekil 1'de verilmiştir.

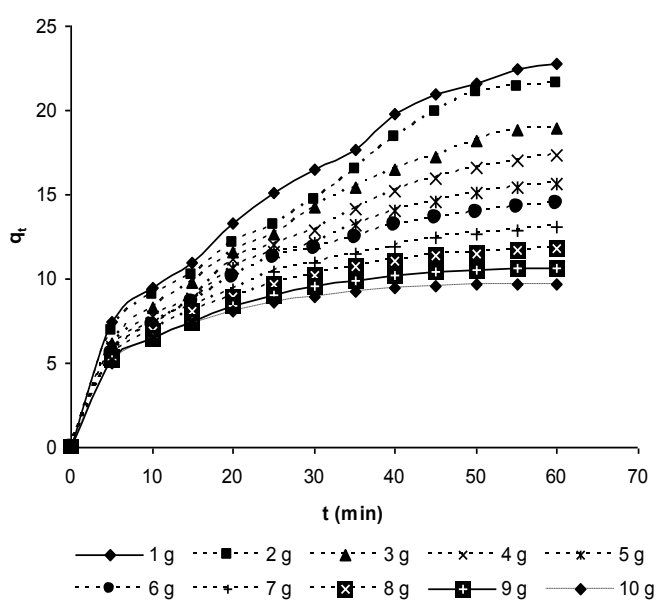

Şekil 1. On farklı GAC dozu için adsorpsiyon denge grafiğ $i$

\subsection{Adsorpsiyon İzotermleri}

RB5 boyar maddesinin GAK tarafindan adsorpsiyonundan elde edilen veri iki parametreli ve ikiden fazla parametreli Adsorpsiyon modellerine uygulanmıştır. İki parametreli modellerin parametreleri lineer regresyon yöntemi ile hesaplanmıştır. İkiden fazla parametreye sahip olan modellerin çözümlenmesi ise non lineer yöntem ile solver program kullanılarak kalıntı karelerin toplaminın minimizasyonuyla gerçekleştirilmiştir. Uygulanan iki parametreleri izotermler ve açıklaması Çizelge 1'de, 3 ve daha fazla parametreleri izotermler ise Çizelge 2'de verilmiştir. RB5 boyar maddesinin GAK tarafindan adsorpsiyonundan elde edilen veri iki parametreli izotermlere uygulanması sonucu 
Reaktif Black 5 Boyar Maddesinin Aktif Karbon Üzerine Adsorpsiyonunun Kinetik ve Adsorpsiyon Modelleri Kullanılarak Incelenmesi

Çizelge 1. Uygulanan iki parametreli adsorpsiyon izotermleri

\begin{tabular}{|c|c|c|}
\hline İzoterm & Eşitlik & Açıklama \\
\hline Fre undlich & $\log q_{e}=\log K_{F}+\frac{1}{n} \log C_{e}$ & 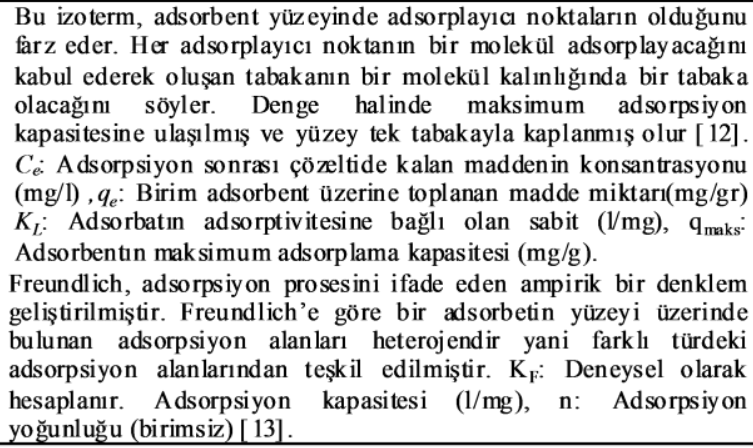 \\
\hline Tempkin & $q_{e}=\frac{R T}{b_{T}} \ln K_{T}+\frac{R T}{b_{T}} \ln C_{e}$ & $\begin{array}{l}\text { Bu izoterm, adsorbe olan maddeler arasındaki etkileşimleri } \\
\text { değerlendiren bir izotermdir. Tempkin izotermi, etkileşimlerden } \\
\text { do lay } 1 \text { adsorpsiyon } 1 \text { sısının, y üzey in kaplanmasıy la lineer olarak } \\
\text { azalacağın } 1 \text { varsayar. } b_{t}: \text { Adsorpsiy on potansiyeli, } \mathrm{K}_{\mathrm{T}} \text { : Tempkin } \\
\text { izoterm sabiti }(\mathrm{L} / \mathrm{mg}), \mathrm{R}: \mathrm{Gaz} \text { sabiti }\left(\mathrm{J} / \mathrm{mol}^{\mathrm{K}} \mathrm{K}\right)[14] \text {. }\end{array}$ \\
\hline $\begin{array}{l}\text { Dubinin- } \\
\text { Rad ushkevich }\end{array}$ & $\begin{array}{c}\ln q_{e}=\ln q_{\max }-B_{D} \varepsilon^{2} \\
\varepsilon=R T \ln \left(1+\frac{1}{C_{e}}\right) \\
\frac{1}{q_{e}^{2}}=\frac{B}{A}-\frac{1}{A} \log C_{e}\end{array}$ & $\begin{array}{l}\text { Dubinin-Radushkevich (D-R) gaz fazından adsorpsiyon için ortaya } \\
\text { konan mikro gözenek hacim doldurma teorisine dayanılarak } \\
\text { türetilmiștir. Bu izoterm adsorbe edilen bir tabakanın çoklu tabaka } \\
\text { karakteri sergilediğini varsayar. D-R adsorpsiyon izotermi, } \\
\text { adsorpsiyon enerjisini hesaplamada kullanılır. B } \mathrm{B}_{\mathrm{D}} \text { : Adsorpsiyon } \\
\text { enerjisi ile ilgili sabit }\left(\mathrm{mol}^{2} \mathrm{~kJ}^{-2}\right), \varepsilon: \text { Polanyi sabiti }[15,16] \text {. } \\
\text { Bu izoterm heterojen gözenek dağılımının varlığında çok tabakalı bir } \\
\text { adsorpsiyonun mevcudiyetini var sayar. A ve B İoterm sabitleri } \\
{[17] \text {. }}\end{array}$ \\
\hline $\begin{array}{l}\text { Flory- } \\
\text { Huggins }\end{array}$ & $\begin{array}{r}\log \frac{\theta}{C_{0}}=\log K_{F H}+n \log (1-\theta) \\
\theta=\left(1-\frac{C_{e}}{C_{0}}\right)\end{array}$ & $\begin{array}{l}\text { Flory-Huggins izotermi, birbiriyle etkileşmey en farklı boyutlardaki } \\
\text { partiküllerin iki boyutlu kafes bir örgü şeklinde davranışını tanımlar } \\
\text { [18]. Sıvı moleküllerinin bir kafes içindeki kürelerin davranısı gibi } \\
\text { davrandığını varsayar. } \theta \text { :Yüzey kapsamının derecesi, } \mathrm{K}_{\mathrm{FH}} \text { : İzoterm } \\
\text { sabiti, n: Somsiyon sitlerindeki iyon sayısı [19]. }\end{array}$ \\
\hline Jovanovic & $q_{e}=q_{m a k s}\left(1-e^{\left(K_{j} C_{e}\right)}\right)$ & 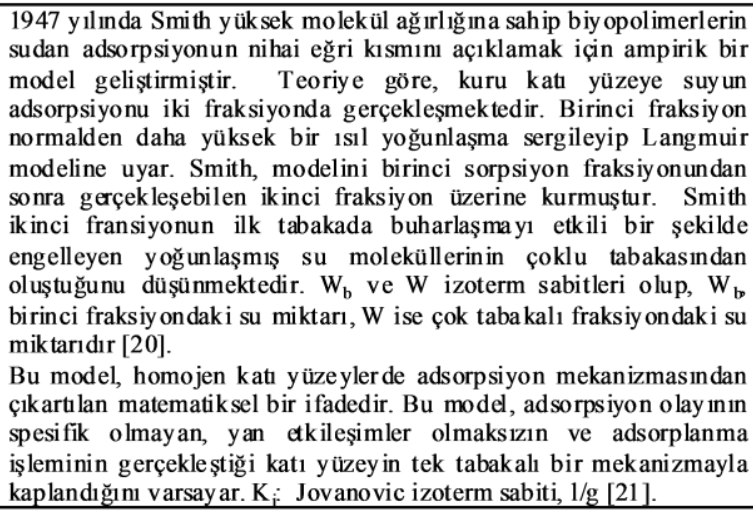 \\
\hline Halsey & $\ln q_{e}=\frac{1}{n} \ln k-\frac{1}{n} \ln C_{e}$ & $\begin{array}{l}\text { Halsey denklemi } 1948 \text { yılında, bir molekülün potansiyel enerjisinin } \\
\text { yüzeye olan uzaklığın ın tersinin bir fonksiyonu olarak değişeceği } \\
\text { öne sürer. Bu eşitliğe göre çok lu tabaka adsorpsiyonunun Van Der } \\
\text { Waals kuvvetlerinin etkisi ile gerçek leştiğini varsayar [22]. }\end{array}$ \\
\hline Henderson & $\ln \left[-\ln \left(1-C_{e}\right)\right]=\ln k+n \ln q_{e}$ & $\begin{array}{l}\text { Henderson eşitliği heterojen yüzeyler adsorpsiyon sistemlerini } \\
\text { tanımlayan bir modeldir. " } \mathrm{n} \text { " sabiti sıcaklığın artmasıyla azalır, buda } \\
\text { sıcaklığın artmasıyla adsorpsiyonun arttığı endotermik proseslerin } \\
\text { varlığında uy um göstermektedir [23]. }\end{array}$ \\
\hline
\end{tabular}


Çizelge 2. Uygulanan üç ve daha fazla parametreli adsorpsiyon izotermler

\begin{tabular}{|c|c|c|}
\hline İzoterm & Eşitlik & Açılama \\
\hline Vieth-Sladek & $q_{e}=K_{V S} C_{e}+\frac{q_{\text {mak }} \beta_{V S} C_{e}}{1+\beta_{V S} C_{e}}$ & 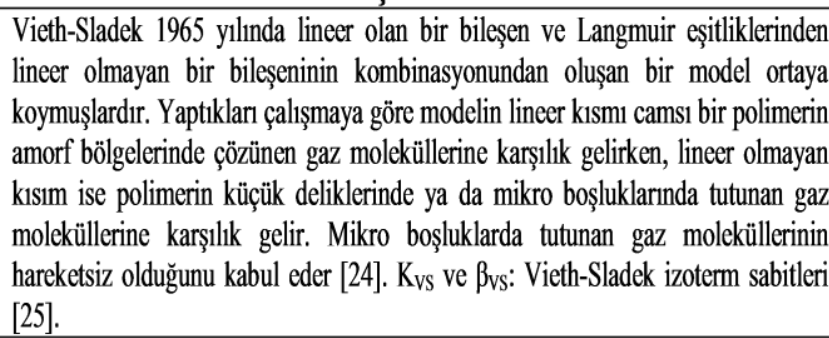 \\
\hline Jossens & $C_{e}=\frac{q_{e}}{H} \exp \left(F q^{p}\right)$ & $\begin{array}{l}\text { Jossens modeli, bir çözz̈nenin bir heterojen yüzey üzerine adsorpsiyonunun } \\
\text { termodinamiklerinden geliştirilen bir modelidir [26]. Jossens modeli, adsorpsiyon } \\
\text { sitlerindeki adsorbent-adsorbat etkileşimlerinin enerjisinin bir dağlımı üzerine } \\
\text { kuruludur [8]. Özellikle hidrokarbonların aktif karbon ile adsorpsiyonun ifade } \\
\text { edilmesinde başarll bir modeldir. Adsorpsiyon kapasitesi açikça konsantrasyonun } \\
\text { fonksiyonu olan bir durum sergiler. H, p ve F sadece sicakliğa bağlı olan Jossens } \\
\text { modeli sabitleridir. }\end{array}$ \\
\hline $\begin{array}{l}\text { Redlich- } \\
\text { Peterson }\end{array}$ & $q_{e}=\frac{K_{r} C_{e}}{1+a_{r} C_{e}^{\beta}}$ & 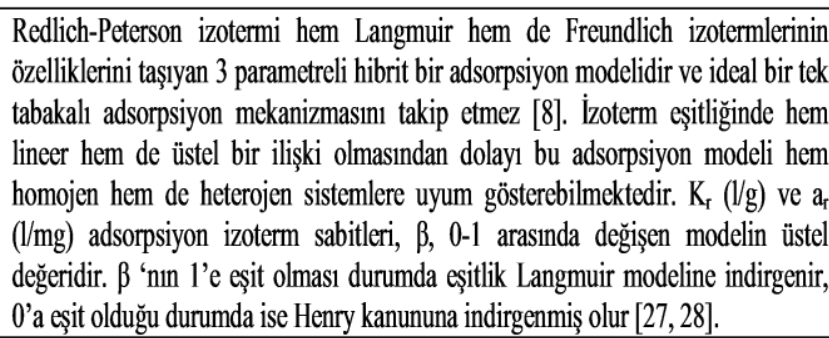 \\
\hline $\begin{array}{l}\text { Radke- } \\
\text { Prausnits }\end{array}$ & $q_{e}=\frac{a_{R} r_{R} C_{e}^{\beta_{R}}}{a_{R}+r_{R} C_{e}^{\beta_{R}-1}}$ & 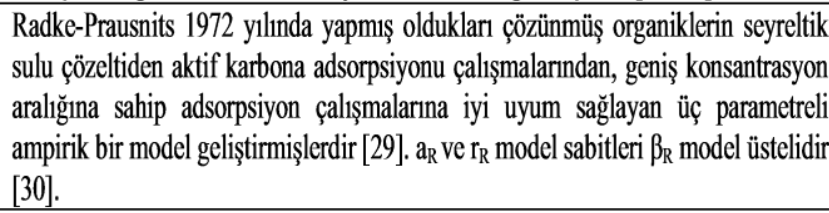 \\
\hline $\begin{array}{l}\text { Koble- } \\
\text { Corrigan }\end{array}$ & $q_{e}=\frac{a C_{e}^{n}}{1+b C_{e}^{n}}$ & $\begin{array}{l}\text { Koble-Corrigan izotermi üç parametreli başka bir adsorpsiyon modelidir. Bu } \\
\text { model de pay ve paydada konstrasyona bağmlı üstel bir ifade vardir. Langmuir } \\
\text { ve Freundlich izotermlerinin birleşmesinden oluşan ve genellikle heterojen yüzey } \\
\text { proseslerine uyum sağlamakakadır. a, b ven Koble-Corrigan sabitleridir [31]. }\end{array}$ \\
\hline $\begin{array}{l}\text { Fritz- } \\
\text { Schlunder }\end{array}$ & $q_{e}=\frac{A C_{e}^{\alpha}}{1+B C_{e}^{\beta}}$ & $\begin{array}{l}\text { Fritz-Schlunder, Langmuir ve Freundlich modellerinden dört parametreli ampirik } \\
\text { bir model geliştirmişlerdir. A ve B Fritz-Schlunder sabitleridir. } \alpha \text { ve } \beta \text { modelin } \\
\text { üstel ifadeleridir ve } \leq 1 \text { dir. Adsorbatın yüksek sivı faz konsantrasyonlarnda } \\
\text { olduğu durumlarda model Freundlich izoterm modeline indirgenmektedir. } \alpha=\beta \\
=1 \text { olmass durumunda eşitlik Langmuir eşitliğine indirgenmektedir. Bu durumda } \\
\text { A Langmuir ifadesinde ki } q_{\text {maks }} \text { a, B sabiti ise Langmuir izoterm sabitine }\left(\mathrm{K}_{\mathrm{L}}\right) \\
\text { dönüşmüşs olur [8]. }\end{array}$ \\
\hline $\begin{array}{l}\text { Weber ve } \\
\text { van Vliet }\end{array}$ & $C_{e}=P_{1} q_{e}^{\left(P_{2} q_{e}^{P_{3}}+P_{4}\right)}$ & $\begin{array}{l}\text { Weber ve van Vliet adsorpsiyon verisini tanımlayabilmek için } 4 \text { parametreli } \\
\text { amprik bir eşitlik geliş̧irmişlerdir. Özellikle hidrokarbonların aktif karbon ile } \\
\text { adsorpsiyonunu iyi tanımlayan bir modeldir. } \mathrm{P}_{1}, \mathrm{P}_{2}, \mathrm{P}_{3} \text { ve } \mathrm{P}_{4} \text { izoterm sabitleridir } \\
\text { [8]. }\end{array}$ \\
\hline
\end{tabular}


Çizelge 3. İki parametreli izoterm sabitleri

\begin{tabular}{|c|c|c|}
\hline İzoterm & Parametre & Değer \\
\hline Langmuir & $\begin{array}{c}\mathrm{q}_{\text {maks }} \\
\mathrm{K}_{L} \\
R^{2}\end{array}$ & $\begin{array}{c}23,58 \\
0,0304 \\
0,986\end{array}$ \\
\hline Freudlich & $\begin{array}{l}1 / n \\
\mathrm{~K}_{F} \\
R^{2} \\
\end{array}$ & $\begin{array}{l}0,259 \\
4,979 \\
0,996 \\
\end{array}$ \\
\hline Tempkin & $\begin{array}{l}\mathrm{b}_{t} \\
\mathrm{~K}_{T} \\
R^{2}\end{array}$ & $\begin{array}{l}0,627 \\
0,772 \\
0,973 \\
\end{array}$ \\
\hline $\begin{array}{c}\text { Dubinin- } \\
\text { Raduskevich }\end{array}$ & $\begin{array}{c}\mathrm{q}_{\text {maks }} \\
\mathrm{B}_{D} \\
R^{2} \\
\end{array}$ & $\begin{array}{c}19,61 \\
0,0112 \\
0,929 \\
\end{array}$ \\
\hline Harkin's-Jura & $\begin{array}{c}\mathrm{a} \\
\mathrm{b} \\
\mathrm{R}^{2}\end{array}$ & $\begin{array}{l}-166,6 \\
-2,698 \\
0,958\end{array}$ \\
\hline Flory-Huggins & $\begin{array}{c}\mathrm{K}_{\mathrm{FH}} \\
\mathrm{n} \\
\mathrm{R}^{2} \\
\end{array}$ & $\begin{array}{c}0.000881 \\
-0,362 \\
0,720 \\
\end{array}$ \\
\hline Smith & $\begin{array}{l}\mathrm{w}_{\mathrm{b}} \\
\mathrm{w} \\
\mathrm{R}^{2}\end{array}$ & $\begin{array}{c}11,145 \\
34,51 \\
0,926\end{array}$ \\
\hline Jovanovic & $\begin{array}{c}\mathrm{q}_{\text {maks }} \\
\mathrm{K}_{\mathrm{j}} \\
\mathrm{R}^{2}\end{array}$ & $\begin{array}{c}18,92 \\
-0,0352 \\
0,779\end{array}$ \\
\hline Halsey & $\begin{array}{c}\mathrm{n} \\
\mathrm{k} \\
\mathrm{R}^{2}\end{array}$ & $\begin{array}{l}-0,622 \\
0,851 \\
0,996\end{array}$ \\
\hline Henderson & $\begin{array}{c}\mathrm{n} \\
\mathrm{k} \\
\mathrm{R}^{2}\end{array}$ & $\begin{array}{c}4,0462 \\
1,32 \times 10^{-6} \\
0,997\end{array}$ \\
\hline
\end{tabular}

hesaplanan izoterm sabitleri ve regresyon katsayıları Çizelge 3'de verilmiștir. Adsorpsiyon süreci 0,986 regresyon katsayıs ile Langmuir izotermine iyi bir uyum göstermiştir. Langmuir izotermi GAK'nın RB5 için maksimum adsorpsiyon kapasitesini ( $\mathrm{q}_{\text {maks }}$ ) 23,58 mg/g olarak tahmin etmiştir. Yapılan deneysel çalışmada en yüksek adsorpsiyon kapasitesi 1 gram GAK için 55. dakika'da (denge anında) $22,45 \mathrm{mg} / \mathrm{g}$ tespit edilmiştir. $\mathrm{Bu}$ durumda Langmuir izoterminin tahmin ettiği maksimum adsorpsiyon kapasitesinin deneysel çalışma ile uyum içersinde olduğu ortaya çıkmaktadır. Freundlich, Halsey ve Henderson izotermleri için regresyon katsayıları sırasılya 0,996, 0,996 ve 0,997 olarak hesaplanmıştır. Bu modeller iki parametreli izotermler arasında adsorpsiyon sürecini en iyi açıklayan modeller olmuştur. Freundlich, Halsey ve Henderson izotermleri heterojen yüzeylerde gerçekleşen adsorpsiyon mekanizmalarını iyi tanımlamaktadırlar $[13,23]$. Aktif karbon yüzeyinin heterojen bir yüzey olması bu durumu açıklamaktadır. Ayrıca Freundlich izotermi için hesaplanan " $1 / \mathrm{n}$ " değerinin sıfira yaklaşması yüzey heterojenitesinin artığını göstermektedir [32]. Çizelge 3 'ten görüleceği üzere Freundlich izotermi için " $1 / n$ ” değeri 0,259 olarak hesaplanmıştır.

Çizelge 3'ten görüleceği üzere Tempkin ve Harkin's-Jura izotermleri için regresyon katsayıları sırasıyla 0,973 ve 0,958 olarak hesaplanmıştır. Regresyon katsayıları göz önüne alındığında adsorpsiyon sürecini bu iki izotermin orta derecede açıklayabildiği ortaya çıkmaktadır. DubininRaduskevich, Flory-Huggins, Smith ve Jovanovich izotermlerinin düşük regresyon katsayıları ile RB5 boyar maddesinin GAK tarafindan adsorpsiyonunu tanımlamada uygun modeller olmadığı ortaya çıkmaktadır. Dubinin-Raduskevich, ve Smith izotermi için tespit edilen regresyon katsayıları sirasiyla 0,929 ve 0,926 iken Flory-Huggins ve Jovanovich izotermleri için sırasıly 0,720 ve 0,779 hesaplanmıştır. Görüldüğü üzere dört izotermde de adsorpsiyon sürecinin tanımlamada yetersiz kalırken bu izotermler içinde Flory-Huggins ve Jovanovich için oldukça düşük regresyon katsayıları ortaya çıkmıştır.

Adsorpsiyon çalışmasından elde edilen veri 3 ve 4 parametreli adsorpsiyon modellerine uygulanmasiyla elde edilen izoterm parametreleri Çizelge 4'de verilmiştir. Uygulanan tüm izotermler içinde 0,998 regresyon katsayısı ile dört parametreli Fritz-Schlunder adsorpsiyon sürecini en iyi tanımlayan izoterm olarak bulunmuştur. Radge-Prausnitz, Redlich-Peterson ve Koble-Corrigan izotermleri Çizelge 4'de görüldüğü üzere 0,995 ile 0,997 arasında regresyon katsayıları ile adsorpsiyon sürecini oldukça yüksek regresyon ile iyi açıklayan modeller olmuştur. Jossens modeli adsorpsiyon sürecini tanımlamada uygun bir model olmadığı düşük regresyon katsayısından anlaşılmaktadır. Vieth-Sladek izotermi orta derecede bir regresyon $(0,974)$ katsayıs1 sergilerlerken tahmin ettiği olan maksimum adsorpsiyon kapasitesi $12,11 \mathrm{mg} / \mathrm{g}$ 'dır. 
Deneysel çalışmada en yüksek adsorpsiyon kapasitesinin 1 g GAK için 22,45 mg/g olduğu göz önüne alındığında, Vieth-Sladek modelinin tahmin ettiği adsorpsiyon kapasitesi deneysel çalışmalar ile iyi bir uyum sergilememektedir.

Yapılan deneysel çalışma ve izoterm modelleri göz önüne alındığında maksimum adsorpsiyon kapasitesini en iyi tahmin eden modelin 23,58 $\mathrm{mg} / \mathrm{g}$ ile Langmuir izotermi olduğu düşünülmektedir.

\subsection{Adsorpsiyon Kinetiği}

Adsorpsiyon kinetiğinin anlaşılması için deneysel çalışmadan elde edilen veri Lagergren, yalancı ikinci derece, Elovich, Avrami ve parçacık içi difüzyon kinetik modellerine uygulanmıştır.

\subsubsection{Lagergren Modeli}

Adsorpsiyon sistemlerinin reaksiyon derecelerini belirlemede birçok kinetik model kullanılmaktadır. Genel olarak kullanılan kinetik model Lagergren tarafından geliştirilen birinci dereceden bir reaksiyon denklemidir [33]. Lagergren eşitliği, adsorpsiyon oranın1, adsorpsiyon kapasitesine göre değerlendiren birinci derece bir eşitliktir [34]. Reaksiyon denklemi (Eşitlik 1) aşağıda ifade edilmiştir.

$\log \frac{q_{e}-q_{t}}{q_{e}}=-\frac{k_{1, a d} t}{2,303}$

$\mathrm{q}_{\mathrm{e}}$ : Denge halinde adsorbe edilen madde miktarı $(\mathrm{mg} / \mathrm{g})$

$\mathrm{q}_{\mathrm{t}}$ : Herhangi bir zamanda adsorbe edilen madde miktar1 $(\mathrm{mg} / \mathrm{g})$

$\mathrm{k}_{1, \mathrm{ad}}$ : Lagergren adsorpsiyon hız sabiti $\left(\mathrm{dk}^{-1}\right)$

Lagergren eşitliği bütün temas zamanına değil, ilk 20-30 dakika'lik sürece uygunluk gösterir. Lagergren eşitliğinin " $\mathrm{k}_{1}$ " değeri başlangıç adsorbat konsantrasyonuna bağlı olarak değişir. Genellikle " $k_{1}$ " değeri adsorbat konsantrasyonunun artmasiyla azalır. [11].

Adsorpsiyon çalışmasından elde edilen verinin Lagergren eşitliğine uygulanması ile elde edilen grafik Shekil 2'de, kinetik parametreler ise Çizelge 5'te verilmiştir. Çizelge 5'ten de görüleceği üzere elde edilen regresyon katsayıları karbon dozunun artmasıyla artış göstermektedir. $1 \mathrm{~g}$ karbon için Lagergren regresyon katsayısı 0,933 iken 10 g karbon için bu değer 0,977 'dir. $6,7,8,9$ ve 10 gram karbon dozları için adsorpsiyon kinetiği Lagergren kinetik modeli tarafindan orta derecede bir uyum sağlamaktadır. $1,2,3,4$ ve 5 gram karbon dozları için Lagergren eşitliği adsorpsiyon kinetiğini açıklamada yetersiz kalmaktadır.

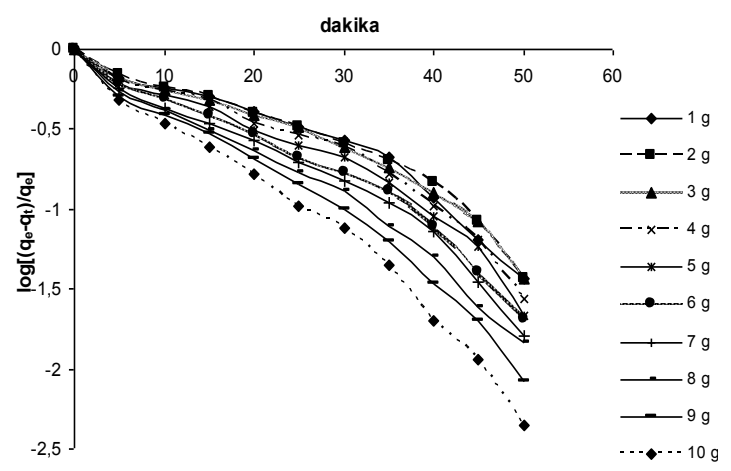

Şekil 2. GAK tarafindan RB5 adsorpsiyonunda lagergren kinetik modeli

Çizelge 5. Lagergren kinetik model sabitleri

\begin{tabular}{|c|c|c|}
\hline $\begin{array}{c}\text { Karbon } \\
\text { Dozu, } \mathbf{g}\end{array}$ & \multicolumn{2}{|l|}{ Parametre } \\
\cline { 2 - 3 } $\mathbf{k}\left(\mathbf{m i n}^{-\mathbf{1}} \mathbf{)}\right.$ & $\mathbf{R}^{\mathbf{2}}$ \\
\hline 1 & 0,0596 & 0,933 \\
\hline 2 & 0,0571 & 0,933 \\
\hline 3 & 0,0575 & 0,946 \\
\hline 4 & 0,0628 & 0,939 \\
\hline 5 & 0,066 & 0,942 \\
\hline 6 & 0,0702 & 0,962 \\
\hline 7 & 0,0727 & 0,960 \\
\hline 8 & 0,0787 & 0,977 \\
\hline 9 & 0,0997 & 0,977 \\
\hline 10 & 0,0129 & 0,999 \\
\hline
\end{tabular}

\subsubsection{Yalancı İkinci Derece Modeli}

Ho tarafından 1995 yılında geliştirilen yalancı ikinci dereceden hız denklemi hızın adsorbat konsantrasyonunda bağımsız, katı fazdaki 
Reaktif Black 5 Boyar Maddesinin Aktif Karbon Üzerine Adsorpsiyonunun Kinetik ve Adsorpsiyon Modelleri Kullanılarak Incelenmesi

adsorpsiyon kapasitesine ve zaman bağlı olduğunu göstermiştir. Yalancı ikinci derece kinetik eşitliği (Eşitlik 2) aşağıda verilmiştir.

$$
\frac{1}{q_{t}}=\frac{1}{q_{e}}+\frac{1}{k_{2} q_{e}{ }^{2}} \frac{1}{t}
$$

$\mathrm{k}_{2}$, Yalancı ikinci dereceden adsorpsiyon hız sabiti (g/mg.dk) [35].

$\mathrm{k}_{2}$, değeri sıklıkla başlangıç adorbat başlangıç konsantrasyonu, $\mathrm{pH}$, sicaklık ve çalkalama şiddeti gibi işletme parametrelerine bağlı olarak değişir. Genellikle $\mathrm{k}_{2}$ değerinin zaman ölçeklendirme faktörü olarak yorumladığı yerlerde, sıvı fazdaki adsorbat konsantrasyonunun artmasıyla $\mathrm{k}_{2}$ değeri azalır. Yalancı ikinci derece eşitliği aynı zamanda Langmuir kinetiklerinin özel bir türü olarak yorumlanır. $\mathrm{Bu}$ yorumlama adsorbat konsantrasyonunun zaman içinde sabit kaldığını ve adsorplanan adsorbat konsantrasyonuna bağlı olduğunu varsayar [11].

Adsorpsiyon çalışmasından elde edilen verinin yalancı ikinci derece kinetik eşitliğine uygulanması ile elde edilen grafik Şekil 3'de, kinetik parametreler ise Çizelge 6'da verilmiştir. Genel olarak adsorpsiyon kinetiği yalancı ikinci derece kinetik modeli, tarafindan iyi bir şekilde açıklanmıştır. 6 gram ve üzeri tüm karbon dozları için elde edilen regresyon katsayıları 0,99'dan büyük olarak hesaplanmıştır.

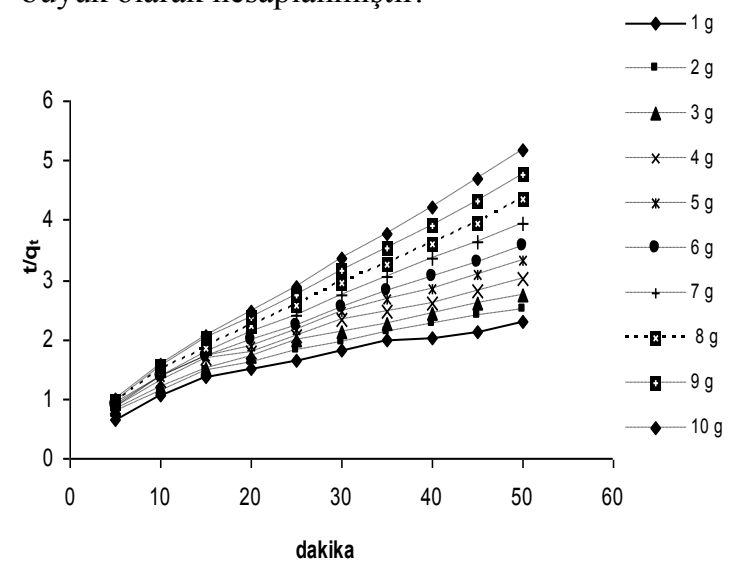

Şekil 3. GAK tarafindan RB5 adsorpsiyonunda yalancı ikinci derece kinetik modeli
Çizelge 6. Yalancı ikinci derece kinetik model sabitleri

\begin{tabular}{|c|c|c|}
\hline \multirow{2}{*}{$\begin{array}{c}\text { Karbon } \\
\text { Dozu, g }\end{array}$} & \multicolumn{2}{|c|}{ Parametre } \\
\cline { 2 - 3 } & k (g.mg.min & \\
& (g.m & $\mathrm{R}^{2}$ \\
\hline 1 & 0,00148 & 0,948 \\
\hline 2 & 0,00161 & 0,960 \\
\hline 3 & 0,00201 & 0,970 \\
\hline 4 & 0,00237 & 0,971 \\
\hline 5 & 0,00328 & 0,983 \\
\hline 6 & 0,00410 & 0,992 \\
\hline 7 & 0,00587 & 0,995 \\
\hline 8 & 0,00748 & 0,996 \\
\hline 9 & 0,00952 & 0,997 \\
\hline 10 & 0,0129 & 0,999 \\
\hline
\end{tabular}

\subsubsection{Elovich Modeli}

Elovich kinetik modeli katı yüzeyler üzerine çeşitli inorganik adsorbatların adsorbsiyon ve desorbsiyon kinetiklerini belirlemek için ortaya koyulmuştur [36]. Elovich eşitliği katı yüzeyin enerjik olarak heterojen olduğunu ve düşük yüzey kapsamında ne desorpsiyonun nede adsorbatların birbirleri arasındaki etkileşimlerinin adsorpsiyon kinetiğini etkileyeceğini varsayar [11]. Elovich eşitliğinin lineer hali (Eşitlik 3) aşağıdaki gibidir:

$q_{t}=\frac{1}{\beta} \ln (\alpha \beta)+\frac{1}{\beta} \ln t$

Elovich eşitliğinde $\alpha, \quad$ adsorpsiyon hızını (mg/g.min), $\beta$ (g/mg) kimyasal sorpsiyon için aktivasyon enerjisini ve yüzey kapsamayı genişletmek ile ilgili sabittir. $\mathrm{Bu}$ sabitler $\mathrm{q}_{\mathrm{t}}$ 'nin $\ln _{\mathrm{t}}$ 'ye karşı grafiğe geçirilmesi ile elde edilir [37]. Elovich eşitliği uzun süreli adsorpsiyon proseslerinde desorpsiyonun ihmal edilmesinden dolayı denge zamanından uzak olan adsorbat adsorbet etkileşimlerinin ilk kısmı ile sinırlanmaktadır [11].

Adsorpsiyon çalışmasından elde edilen verinin Elovich kinetik eşitliğine uygulanması ile elde edilen grafik Şekil 4'de, kinetik parametreler ise Çizelge 7'de verilmiştir. Elovich modeli 7, 8, 9 ve 10 gram karbon dozları için 0,99'dan büyük regresyon katsayıları ile kinetik süreci 
tanımlamada yeterli bir model olmuştur. Ancak bunun altındaki karbon dozları için orta derecece bir uyum sergilemiştir.

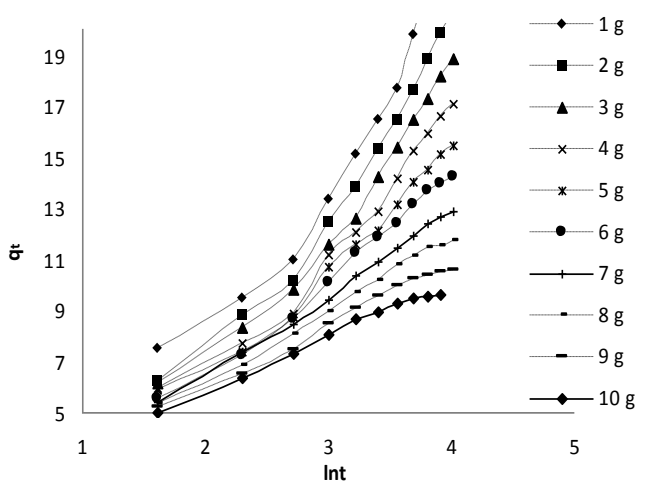

Şekil 4. GAK tarafından RB5 adsorpsiyonunda Elovich kinetik modeli

Çizelge 7. Elovich Kinetik Model Sabitleri

\begin{tabular}{|c|c|c|c|}
\hline \multirow{2}{*}{$\begin{array}{c}\text { Karbon } \\
\text { Dozu, }\end{array}$} & \multicolumn{3}{|c|}{ Parametre } \\
\cline { 2 - 4 } & $\boldsymbol{\alpha}$ & $\boldsymbol{\beta}$ & $\mathbf{R}^{\mathbf{2}}$ \\
\hline 1 & 2,968 & 0,149 & 0,943 \\
\hline 2 & 2,64 & 0,16 & 0,969 \\
\hline 3 & 2,622 & 0,18 & 0,963 \\
\hline 4 & 2,536 & 0,202 & 0,964 \\
\hline 5 & 2,677 & 0,234 & 0,976 \\
\hline 6 & 2,785 & 0,259 & 0,988 \\
\hline 7 & 3,21 & 0,31 & 0,995 \\
\hline 8 & 3,507 & 0,357 & 0,994 \\
\hline 9 & 3,946 & 0,414 & 0,992 \\
\hline 10 & 4,48 & 0,47 & 0,991 \\
\hline
\end{tabular}

\subsubsection{Avrami Kinetik Modeli}

Kontak zamanı ve sıcaklığın bir fonksiyonu olarak adsorpsiyon oranlarındaki değişimin belirlenmesinde mevcut adsorpsiyon kinetik modelleri yetersiz kalabilmektedir. $\mathrm{Bu}$ gibi durumlarda bazı spesifik adsorpsiyon kinetik parametrelerinin belirlenmesinde Avrami kinetik modeli geliştirilmiştir. Avrami kinetik eşitliği (Eşitlik 4) aşağıda verilmiştir.

$$
\ln \left[\ln \left(\frac{q_{e}}{q_{e}-q_{t}}\right)\right]=n \ln k_{a v}+n \ln t
$$

$\mathrm{k}_{\mathrm{av}}$ : Avrami kinetik sabiti

$\mathrm{n}$ : Adsorpsiyon mekanizmasının değişimi ile ilgili sabit $k_{a v}$ ve $n \ln \left(\ln \left(\mathrm{q}_{\mathrm{e}} / \mathrm{q}_{\mathrm{e}}-\mathrm{q}_{\mathrm{t}}\right)\right)^{\prime}$ nin $\ln _{\mathrm{t}}{ }^{\prime}$ ye karş1 grafiğe geçirilmesi ile elde edilir [38].

Adsorpsiyon çalışmasından elde edilen verinin Avrami kinetik eşitliğine uygulanması ile elde edilen grafik Şekil 5'te, kinetik parametreler ise Çizelge 8'de verilmiştir. Çizelge 7'den de görüleceği üzere Avrami kinetik modeli için elde edilen regresyon katsayıları diğer kinetik modeller ile karşılaştırıldığında daha düşük kalmaktadır. Elde edilen en yüksek regresyon katsayısı 10 gram karbon dozu için 0,966'dır. Bu sonuçlar göz önüne alındığında Avrami eşitliği adsorpsiyon kinetiğinin tanımlanmasında orta derecede bir ilişki ortaya koymuştur.

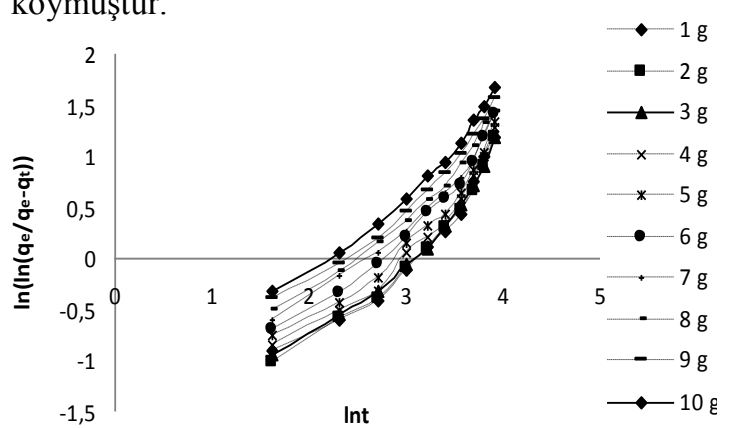

Şekil 5. GAK tarafindan RB5 adsorpsiyonunda Avrami kinetik modeli

Çizelge 8. Avrami Kinetik Model Sabitleri

\begin{tabular}{|c|c|c|l|}
\hline \multirow{2}{*}{ Karbon Dozu, g } & \multicolumn{3}{|c|}{ Parametre } \\
\cline { 2 - 4 } & $\mathbf{n}$ & $\mathbf{k}_{\text {av }}$ & $\mathbf{R}^{2}$ \\
\hline 1 & 0,905 & 0,0538 & 0,916 \\
\hline 2 & 0,916 & 0,0523 & 0,944 \\
\hline 3 & 0,886 & 0,0550 & 0,943 \\
\hline 4 & 0,899 & 0,0591 & 0,933 \\
\hline 5 & 0,877 & 0,0657 & 0,934 \\
\hline 6 & 0,892 & 0,0727 & 0,952 \\
\hline 7 & 0,839 & 0,0807 & 0,956 \\
\hline 8 & 0,841 & 0,0898 & 0,961 \\
\hline 9 & 0,846 & 0,0945 & 0,958 \\
\hline 10 & 0,868 & 0,1120 & 0,966 \\
\hline
\end{tabular}


Reaktif Black 5 Boyar Maddesinin Aktif Karbon Üzerine Adsorpsiyonunun Kinetik ve Adsorpsiyon Modelleri Kullanılarak Incelenmesi

\subsubsection{Parçacık İçi Difüzyon}

Adsorpsiyon işlemine parçacık içi difüzyonunun etkisinin bulunması ise $\mathrm{q}_{\mathrm{t}}$ değerinin zamanın kareköküne karşı grafiği çıkartılarak anlaşılır. Eğim hız sabitini verecektir [39]. Parçacık içi difüzyon eşitliği (Eşitlik 5) aşağıdaki gibidir.

$$
k_{p}=\frac{q_{t}}{t^{0.5}}
$$

$\mathrm{q}_{\mathrm{t}}$ : $\mathrm{t}$ zamanında birim adsorbent üzerine adsorplanan miktar $(\mathrm{mg} / \mathrm{g})$

t: zaman $(\mathrm{dk})$

$\mathrm{k}_{\mathrm{p}}$ : Parçacık içi difüzyon hız sabiti $\left(\mathrm{mg} / \mathrm{g} \mathrm{dk}^{0,5}\right)$

Adsorpsiyon çalışmasından elde edilen verinin parçacık içi difüzyon eşitliğine uygulanması ile elde edilen grafik Şekil 6'da, parametreler ise Çizelge 9'da verilmiştir.

Çizelge 9'dan görüleceği üzere parçacık içi difüzyon katsayıları karbon dozunun artmasıyla azalmıştır. Parçacık içi difüzyonun sıvı fazdaki adsorbat konsantrasyonun artmasıyla arttığı bilinmektedir. Karbon dozunun artmasiyla siv1 fazdaki kalıntı boyar madde konsantrasyonu daha hızlı bir şekilde azalmaktadır. $\mathrm{Bu}$ durumda parçacık hızı difüzyonunun da azalması beklenen bir durumdur.

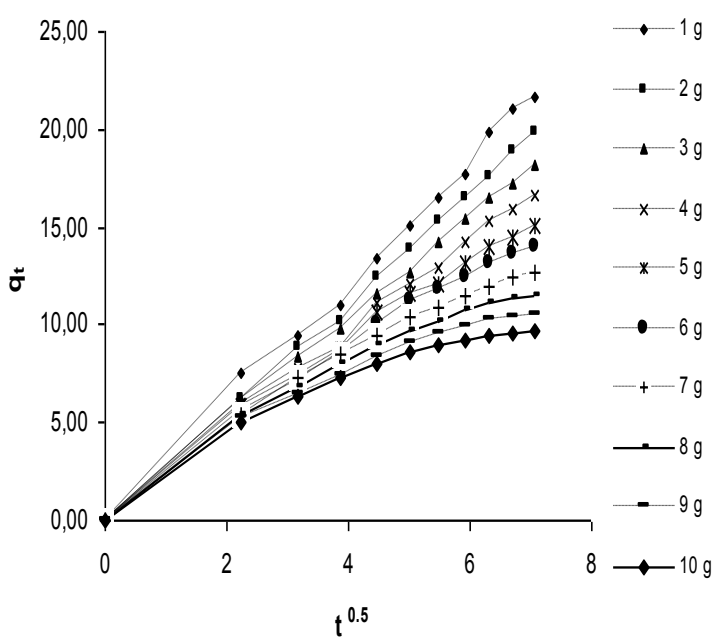

Şekil 6. GAK tarafindan RB5 adsorpsiyonunda parçacık içi difüzyonu
Çizelge 9. Parçacık içi difüzyon sabitleri

\begin{tabular}{|c|c|c|c|}
\hline \multirow{2}{*}{$\begin{array}{c}\text { Karbon } \\
\text { Dozu, }\end{array}$} & \multicolumn{3}{|c|}{ Parametre } \\
\cline { 2 - 4 } & $\boldsymbol{\alpha}$ & $\boldsymbol{\beta}$ & $\mathbf{R}^{\mathbf{2}}$ \\
\hline 1 & 2,968 & 0,149 & 0,943 \\
\hline 2 & 2,640 & 0,160 & 0,969 \\
\hline 3 & 2,622 & 0,180 & 0,963 \\
\hline 4 & 2,536 & 0,202 & 0,964 \\
\hline 5 & 2,677 & 0,234 & 0,976 \\
\hline 6 & 2,785 & 0,259 & 0,988 \\
\hline 7 & 3,210 & 0,310 & 0,995 \\
\hline 8 & 3,507 & 0,357 & 0,994 \\
\hline 9 & 3,946 & 0,414 & 0,992 \\
\hline 10 & 4,480 & 0,470 & 0,991 \\
\hline
\end{tabular}

Adsorpsiyon kinetiğini anlamak için kullanılan eşitliklerden elde edilen sonuçlar göz önüne alındığında adsorpsiyon kinetiğini en iyi tanımlayan modelin yalancı ikinci derece kinetik model olduğu ortaya çıkmaktadır. Elde edilen bulgular adsorpsiyon kinetiğini üzerine karbon dozunun etkili olduğunu göstermiştir.

\section{SONUÇ}

Bu çalışmada RB5 boyar maddesinin granül aktif karbon tarafından adsorpsiyon mekanizmasının açıklanmasında çeşitli adsorpsiyon izotermleri ve kinetik modelleri kullanılmıştır. İki ve ikiden fazla parametreli adsorpsiyon modelleri olmak üzere 17 farklı izoterm eşitliği kullanılmıştır. İki parametreli izoterm modelleri arasında adsorpsiyon sürecini en iyi açıklayan modeller, heterojen yüzeylerde adsorpsiyonu iyi tanımlayan Freundlich, Halsey ve Henderson izotermleri olmuştur. Aktif karbon yüzeyinin heterojen bir yapıya sahip olması bu durumu açıklamaktadır. Üç ve daha fazla parametreye sahip olana modeller arasında Redlich-Peterson, Radge-Prausnitz, Koble-Corrigan, Fritz-Schlunder, Weber-van Vliet modelleri ile 0,99'dan büyük regresyon katsayıları adsorpsiyon sürecini en iyi tanımlayan izotermler olmuştur. Granül aktif karbonun RB5 
için maksimum adsorpsiyon 23,58 mg/g kapasitesi Langmuir izoterminden elde edilmiştir. Langmuir izoterminin tahmin ettiği maksimum adsorpsiyon kapasitesi deneysel çalışmalar ile elde edilen adsorpsiyon kapasitesi ile en iyi uyum gösteren değer olmuştur. Kinetik sürecin açıklanması için kullanılana eşitlikler içerisinde en yüksek regresyon katsayıları ile kinetik süreci tanımlayan modelin yalancı ikinci derece kinetik modeli olduğu ortaya çıkmıştır.

\section{KAYNAKLAR}

1. Senthilkumaar S, Kalaamani P, Porkodi K, Varadarajan PR, Subburaam CV. 2006. Adsorption of Dissolved Reactive Red Dye from Aqueous Phase onto Activated Carbon Prepared from Agricultural Waste. Bioresource Technology, 97/14: 1618-25.

2. Ahmad MA, Alrozi R. 2011. Optimization of Rambutan Peel Based Activated Carbon Preparation Conditions for Remazol Brilliant Blue Removal. Chemical Engineering Journal, 168/1: 280-85.

3. Ip AWM, Barford JP, McKay G. 2009. Reactive Black Dye Adsorption/Desorption onto Different Adsorbents: Effect of Salt, Surface Chemistry, Pore Size and Surface Area. Journal of Colloid and Interface Science, 337/1: 32-38.

4. Walker GM, Weatherley LR. 1997. Adsorption of Acid Dyes onto Granular Activated Carbon in Fixed Beds, Water Research, 31/8; 2093 101.

5. Hameed BH, Mahmoud D.K, Ahmad A.L. 2008. Equilibrium Modeling and Kinetic Studies on the Adsorption of Basic Dye By a Low Cost Adsorbent: Coconut (Cocos Nucifera) Bunch Waste. Journal Hazardous Materials, 158/1: 65-72.

6. Mittal A, Gupta VK, Malviya A., Mittal J2008. Process Development for the Batch and Bulk Removal and Recovery of a Hazardous, WaterSoluble Azo Dye Metanil Yellow by Adsorption Over Waste Materials (bottom ash and de-oiled soya). Journal Hazardous Materials, 151/2-3: 821-32.
7. Allen S.J., Mckay G., Porter J.F., 2004. Adsorption Isotherm Models for Basic Dye Adsorption by Peat in Single and Binary Component Systems. Journal of Colloid and Interface Science, 280( 2): 322333.

8. Hamdaoui O, Naffrechoux E. 2007. Modeling of Adsorption Isotherms of Phenol and Chlorophenols onto Granular Activated Carbon. Part II. Models with more than Two Parameters. J Hazard Mater. 147(1-2):401-11.

9. Kinniburgh D. G., 1986. General Purpose Adsorption Isotherms, Environ. Sci. Technol., 20 (9), pp 895-904.

10. Aksu, A., Sag, Y., Nourbakhsh, M., Kutsal. T., 1993. Atıksulardaki Bakır, Krom ve Kurşun İyonlarının Çeşitli Mikroorganizmalarla Adsorplanarak Giderilmesinin Karşılaştırmalı Olarak İncelenmesi, Turkish Journal Of Engineering \& Environmental Sciences, 19: 285-293.

11. Guptaa Susmita Sen, Krishna G. Bhattacharyya, 2011. Kinetics of Adsorption of Metal Ions on Inorganic Materials: A review. Advances in Colloid and Interface Science. 162(1-2):39-58.

12. Benefield, L. D., Judkins, J. F., Weand, B. L., 1982. Process Chemistry for Water and Wastewater Treatment. Prentice-Hall, Inc, Englewood Cliffs, New Jersey.

13. Chiou, M.-S., Li, H.-Y., 2002. Equilibrium And Kinetic Modeling of Adsorption of Reactive Dye on Cross-Linked Chitosan Beads. Journal of Hazardous Materials, 93(2): 233-248.

14. Farah J.F., 1 Nour Sh. El-Gendy. 2013. Performance, Kinetics and Equilibrium in Biosorption of Anionic Dye Acid Red 14 by the Waste Biomass of Saccharomyces cerevisiae as a Low-Cost Biosorbent. Turkish J Eng Env Sci. 37: 146-161.

15. Onyango Ms, Kojima Y, Aoyi O, 2004. Bernardo Ec, Matsuda H., Adsorption Equilibrium Modeling and Solution Chemistry Dependence of Fluoride Removal from Water by Trivalent-Cationexchanged Zeolite F-9. J Colloid Interface Sci. 279: 341-350.

16. Dabrowski A. 2001. Adsorption from Theory to Practice, Advances in Colloid and Interface Science, 93/1-3: 135-224. 
17. A. Gurses, C. Dogar, M. Yalcin, M. Acikyildiz,R. Bayrak, and S. Karaca, 2006. The Adsorption Kinetics of the Cationic Dye Methylene Blue Onto Clay J. of Haz. Mat.,vol. 131, pp. 217-228.

18. Liu, Y., Liu, Y., 2008. Biosorption Isotherms, Kinetics and Thermodynamics, Separation and Purification Technology, 61, (3), 229-242.

19. Horsfall M Jnr, Spiff AI, Effect of Temperature on the Sorption of $\mathrm{Pb}^{2+}$ and $\mathrm{Cd}^{+2}$ Ions from Aqueous Solutions by Caladium (Wild Cocoyam) Biomass, Electronic j. Biotechnol; (8) 2005.

20. Ricardo D. Andrade P.1,2, Roberto Lemus M.3, Carmen E. Pérez C. 2011. Models of Sorption Isotherms for Food: Uses and Limitations Vitae, Revista de la Facultad de Química Farmacéutica ISSN 0121-4004/ ISSNe 2145-2660. Volumen 18(3): 325-334.

21. Hadi M., Mohammad R. S., Gordon M., 2010. Equilibrium Two-Parameter Isotherms of Acid Dyes Sorption by Activated Arbons: Study of Residual Errors. Chem. Eng. Journ. 160: 408416.

22. Zorlugenç F., 2010. Ozmotik Dehidrasyon Uygulamasının Trabzon Hurması Meyvelerinin Kuruma Davranışı ve Ürün Kalitesi Üzerine Etkileri. Çukurova Üniversitesi Fen Bilimleri Enstitüsü, Gıda Mühendisliği Anabilim Dalı, Doktora Tezi.

23. Canan Akmil Basar, 2006. Applicability of the Various Adsorption Models of Three Dyes Adsorption onto Activated Carbon Prepared Waste Apricot Journal of Hazardous Materials B135, 232-241.

24. J. Crank., 1975. The Mathematics of Diffusion. Second Edition. Oxford University Pres. p: 329.

25. Alexandro M.M. Vargas, Andre L. Cazetta, Marcos H. Kunita, Tais L. Silva, Vitor C. Almeida., 2011. Adsorption of Methylene Blue on Activated Carbon Produced from Flamboyant Pods (Delonix regia): Study of Adsorption Isotherms and Kinetic Models. Chemical Engineering Journal 168, 722-730.

26. Sheng H. Lin, Cheng P. Huang. 2001. Adsorption of Hydrazoic Acid from Aqueous Solution by Macroreticular Resin. Journal of Hazardous Materials B84, 217-228.
27. Redlich, O., Peterson, D.L., 1959. A Useful Adsorption Isotherm, J. Physical Chemistry. 63: 1024- 1026.

28. Gimbert, F., Morin-Crini. N., Renault, F., Badot, P.M., Crini, G., 2008. Adsorption Isotherm Models for Dye Removal by Cationized Starch-Based Material in a Single Component System: Error Analysis. Journal of Hazardous Materials 157: 34-46.

29. Radke C.J, J.M. 1972. Prausnitz. Adsorption of Organic Solutes from Dilute Aqueous Solutions on Activated Carbon Ind. Eng. Chem. Fundam., 11: 445-450.

30. T. V. N. Padmesh, K. Vijayaraghavan G. Sekaran M. Velan., 2006. Application of Two and Three-Parameter Isotherm Models: Biosorption of Acid Red 88 onto Azolla microphylla. Bioremediation Journal, 10(1-2): 37-44.

31. R.P. Han, J.J. Zhang, P. Han, Y.F. Wang, Z.H. Zhao, M.S. Tang 2009. Study of Equilibrium, Kinetic and Thermodynamic Parameters About Methylene Blue Adsorption onto Natural Zeolite, Chem. Eng. J. 145, 496-504.

32. Haghseresht F, Lu G., 1998. Adsorption Characteristics of Phenolic Compounds onto Coal-Reject-Derived Adsorbents Energy Fuels, 12 pp. 1100-1107.

33. Ho, Y.S., Wang, C.C., 2006. Pseudo-Isotherms for the Sorption of Cadmium Ions Onto Tree Fern. Process Biochem., 39: 759-763.

34. Ho Yuh-Shan. Review of Second-Order Models for Adsorption Systems. Journal of Hazardous Materials B. 136: 681-689.

35. H. Ghoveisi, J. Farhoudi, MH. Omid, A. Mahdavi Mazdeh, 2013. Comparison of Different Methods for Linear Regression of Pseudo Second Order Adsorption Kinetics of Cadmium, Journal of Civil Engineering and Urbanism, Volume 3, Issue 2: 73-76.

36. Sparks, D.L., 2002. Environmental Soil Chemistry. Academic Press, Second Edition, 350 p., USA.

37. Ho, Y. S., Mckay, G., 1999. Comparative Sorption Kinetic Studies of Dye and Aromatic Compounds onto Fly Ash. J. Environ. Sci. Health, A34 (35): 1179-1204.

38. Antonio R. Cestari, Eunice F.S. Vieira, Glaucia S. Vieira, Luis E. Almeida. 2006. The Removal 
of Anionic Dyes from Aqueous Solutions in the Presence of Anionic Surfactant Using Aminopropylsilica-A Kinetic Study, Journal of Hazardous Materials B138, 133-141.

39. Waranusantigul $\mathrm{P}, \quad$ Pokethitiyook $\mathrm{P}$, Kruatrachue M, Upatham ES. 2003. Kinetics of Basic Dye (Methylene Blue) Biosorption by Giant Duckweed (Spirodela polyrrhiza), Environmental Pollution; 125/3: 385-92. 
